\title{
From globalism to localism: How structural economic shifts can support the local food movement
}

\author{
Review by Emily Duncan* \\ University of Guelph
}

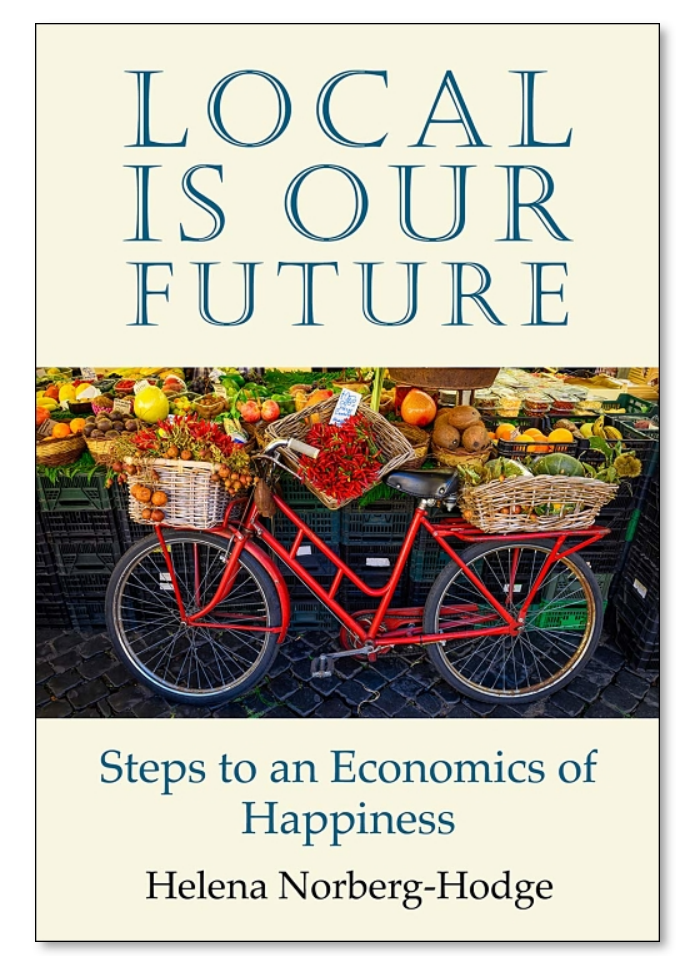

Review of Local Is Our Future: Steps to an Economics of Happiness, by Helena Norberg-Hodge. (2019). Local Futures. Available as ebook and paperback; 160 pages. Publisher's website: https://www.localfutures.org/publications/local-is-ourfuture-book-helena-norberg-hodge/

Submitted September 23, 2020 / Revised October 5, 2020 / Published online March 31, 2021

Citation: Duncan, E. (2021). From globalism to localism: How structural economic shifts can support the local food movement [Book review]. Journal of Agriculture, Food Systems, and Community Development, 10(2), 599-601. https://doi.org/10.5304/jafscd.2021.102.047

Copyright (C) 2021 by the Author. Published by the Lyson Center for Civic Agriculture and Food Systems. Open access under CC-BY license.

ocal is Our Future was published shortly before
the rise of the COVID-19 pandemic, yet it makes a timely contribution critiquing economic globalization given the experiences of 2020. It emphasizes the need for shorter supply chains and champions local food systems by focusing on the

* Emily Duncan is a Ph.D. candidate in the Department of Geography, Environment and Geomatics at the University of Guelph, where she studies global food security and sustainable agriculture. Her research investigates the social impacts of digital agricultural technologies on the food system. She is a coordinator of the Guelph Tool Library, which works to build a resilient sharing economy in her community. She can be contacted at Department of Geography, Environment and Geomatics, University of Guelph; 50 Stone Road East; Guelph, Ontario N1G 2W1 Canada; edunca01@uoguelph.ca structural forces that currently control the food system.

In the first three chapters, Norberg-Hodge explains and details the costs of economic globalization, which provides an adept introduction to understanding the structural impacts of financial deregulation on health, food security, environmental consequences, and growing inequality. The fourth chapter covers a topic that might seem unlikely to be included in a book on local futures, as it describes the rise of extremism, yet this is a crucial analysis for current events. This book was published before the Black Lives Matter demonstrations that occurred around the world in summer 2020; however, it provides a contextual 
backdrop for how the globalized financial system promotes economic insecurity that can lead to the adoption of a false narrative by the far right, as observed by the backlash to BIPOC (Black, Indigenous, and People of Color) communities demonstrating the need for increased equality.

Chapters 5, 6, and 7 provide arguments for localization through pertinent examples of grassroots initiatives of local food enterprises. This section is important because localization can often be romanticized without describing the actionable steps needed to work toward this goal. In this case, the author clearly lays out the policy changes required to move toward a local future, including updating trade treaties, financial regulation, and taxation policies, among others. These chapters also demonstrate that the local food movement can lead other sectors, such as energy, finance, and education, toward improved governance structures. The eighth chapter spells out common objections to localization, which helps to build the argument for a local future by addressing concerns. These objections to localization include the common perceptions that globalization is needed to alleviate poverty, that cities are more efficient, and that fair trade can ameliorate some of the problems of globalization. Norberg-Hodge addresses these concerns by explaining that, in fact, globalization has led to poverty in many areas, cities require huge amounts of resources for energy and waste disposal, and while fair trade standards can offer guidance, ultimately production should be geared toward local consumption.

The ninth chapter returns to globalization, discussing more evidence of its drivers. It would be better situated perhaps in the opening chapters on this topic, as it feel a bit out of place in the later section of the book. Finally, the last three chapters (10-12) appeal to the reader's emotions through a nostalgic rethinking of past economies, a call for 'big picture activism' and a reiteration of the proposed movement toward an economics of happiness through localization. While a nostalgic strategy is unlikely to appeal to any technologist readers, the 'big picture activism' message has widespread appeal. It is a call for informational campaigns that challenge assumptions about globalization and start to construct a new narrative about the realities of the economic and environmental crises. Ensuring that people have an understanding of the consequences of globalization is the first step to changing the system. The book finishes with a dialogue between the author and the well-known proponent of small-scall agriculture, Wendell Berry. This conversation does not present new information and primarily serves to agree with the arguments put forward in the book. Berry's contribution stylistically might have been more informative to readers as a foreword to the book or with quotations worked into the chapters.

Overall, while this book is less likely to appeal to an academic audience because it does not feature rigorous peer-reviewed evidence, it is highly useful to provide an introduction to the topic of localization given the straightforward arguments, clear examples, and attention to counterarguments. This book will make proponents of globalized agriculture reconsider the possibilities of local food systems, as Norberg-Hodge draws on important arguments developed by critical food scholars. For example, she highlights the fact that we already produce more than enough food globally, yet close to 800 million people go hungry (Patel, 2012; Tomlinson, 2013) and that there needs to be a focus on a portfolio of solutions that support local food, address unregulated markets through policy, and create more equity in the food system (Fraser et al., 2016). For those working on the frontlines of the local food movement, the clarity of this book is likely to reinvigorate efforts to build and sustain local food endeavors.

A prominent example throughout the book is the author's own experiences observing the changes globalization brought to a small rural community located in Ladakh, in the much disputed territory between India, Pakistan, China, and the Tibet Autonomous Region. This is an example that would be better supported with a critical reflection on positionality, as Norberg-Hodge runs the risk in a few instances of essentializing village life in the Global South. She reveres what she refers to as the "old culture" and assumes that this community was better off without modern developments. As she is a Swedish woman who is not part of this community, it is perhaps a presumptive position that does not capture the nuances of life 
in Ladakh. While some of these communities might be exemplary in how they embrace local food systems, there is undeniably also a need for globalized technologies to improve child and maternal health and reduce the drudgery of some agricultural tasks.

This book lays out a clear blueprint for how to take 'steps to an economics of happiness' through changing the structural forces that shape our food system. These arguments help to provide a more balanced approach to advocating for a local food movement, when often consumer agency is placed at the forefront of change. The hope of a more local future based on an economics of happiness is what is most needed in these highly uncertain times.

\section{References}

Fraser, E., Legwegoh, A., KC, K., CoDyre, M., Dias, G., Hazen, S., ... Yada, R. (2016). Biotechnology or organic? Extensive or intensive? Global or local? A critical review of potential pathways to resolve the global food crisis. Trends in Food Science \& Technology, 48, 78-87. https://doi.org/10.1016/j.tifs.2015.11.006

Patel, R. (2012). Stuffed and starved: The hidden battle for the world food system (Second ed.). Melville House.

Tomlinson, I. (2013). Doubling food production to feed the 9 billion: A critical perspective on a key discourse of food security in the UK. Journal of Rural Studies, 29, 81-90. https://doi.org/10.1016/j.jrurstud.2011.09.001 